\title{
Neural Activation by Milnacipran and Memory Extinction
}

\author{
Hisahito Ishida $^{1}$, Masaaki Iwata ${ }^{1}$, Yukihiko Shirayama ${ }^{2 *}$, Katsumasa Muneoka ${ }^{3}$ \\ ${ }^{1}$ Department of Neuropsychiatry, Faculty of Medicine, Tottori University, Tottori, Japan \\ ${ }^{2}$ Department of Psychiatry, Teikyo University Chiba Medical Center, Chiba, Japan \\ ${ }^{3}$ Department of Anatomy I, Showa University School of Medicine, Tokyo, Japan \\ Email: *Shirayama@rapid.ocn.ne.jp
}

Received September 8, 2011; revised November 3, 2011; accepted November 21, 2011

\begin{abstract}
Background: Among neurotransmitter influencing memory formation, the noradrenergic system has been recognized as an important system. Memory formation involves various regions including the prefrontal cortex, hippocampus, amygdala and septum. Method: We investigated the effects of milnacipran on passive avoidance task and evaluated Fos counting in the prefrontal cortex, hippocampus, septum, amygdala and nucleus accumbens. Results: The milnacipran-treated rats $(20 \mathrm{mg} / \mathrm{kg}, 4$ days) showed a significant decrease in the number of Fos-immunoreactive cells in the infralimbic portion of prefrontal cortex, the shell portion of nucleus accumbens and the CA1 region of hippocampus, but a significant increase in the Fos counts in the lateral septum with no changes in the Fos counts in the striatum and amygdala. The milnacipran-treated rats showed amelioration in memory extinction (although not statistically significant), but not in memory acquisition and consolidation in the passive avoidance test. Conclusion: The differential activation of the brain regions might be possible sites for ameliorating memory extinction as well as antidepressant effects.
\end{abstract}

Keywords: Milnacipran; Passive Avoidance Task; Prefrontal Cortex; Nucleus Accumbens; Hippocampus; Septum

\section{Introduction}

Depression often demonstrated recurrent considering the past, indicating ameliorated memory extinction. Depression also enhanced sensitivity to aversive stressful events. Indeed, depressed patients showed explicit memory deficits [1]. It was reported that pre-training administration of various antidepressants (amitriptyline, maprotiline and fluoxetine) did not affect inhibitory avoidance learning $[2,3]$. Furthermore, duloxetine failed to affect short- and long-term memory in the inhibitory avoidance task in mice [4]. However, a recent review extrapolated that the effects of SSRIs are memory phase-dependent, being inhibitory during acquisition/consolidation and facilitatory during consolidation and retrieval [5].

Among antidepressants, milnacipran is classified as a serotonin norepinephrine reuptake inhibitor (SNRI) similarly to venlafaxine and duloxetine. Behavioral studies demonstrated that milnacipran was active not only in the forced swim test, a model of antidepressant efficacy, but also in the conditioned fear stress test, an animal model of anxiety [6]. Neurochemically, acute and subchronic milnacipran treatment increased basal extracellular norepinephrine concentrations in the prefrontal cortex $[6,7]$. Furthermore, repeated administration of milnacipran increased dopamine levels in the prefrontal cortex [8].

*Corresponding author.
Among neurotransmitter influencing memory formation, the noradrenergic system has been recognized as an important system in many behavioral paradigms [9]. Memory formation involves various regions including the prefrontal cortex, hippocampus, amygdala and septum [9]. Therefore, we investigated the effects of milnacipran on passive avoidance task and evaluated Fos counting in the prefrontal cortex, hippocampus, septum, amygdala and nucleus accumbens.

\section{Material and Methods}

\subsection{Animals}

Animal-use procedures were in accordance with the Tottori University Guide for the Care and Use of Laboratory Animals and were approved by the Tottori University Animal Care and Use Committee. All experiments conformed to international guidelines on the ethical use of animals. Male Sprague-Dawley rats were used (6 weeks old). Animals were housed under a 12 hour-light/dark cycle with free access to food and water. Rats were subcutaneously injected once daily with milnacipran hydrochloride $(20 \mathrm{mg} / \mathrm{kg})$ dissolved in saline for 4 days. The rationale for choosing the dose of milnacipran stems from previous animal studies that milnacipran $20 \mathrm{mg} / \mathrm{kg}$ exerted antidepressant-like effects [10]. The duration of drug regimen was based on a recent study [8]. A control 
group was injected with saline alone. Milnacipran hydrochloride was kindly supplied from Asahi-Kasei Co.

\subsection{Passive Avoidance Test}

A passive avoidance test was conducted according to standard procedures with the following modification [4]. The apparatus was divided into two compartments by a retractable door: a bright safe compartment and a dark shock compartment (Gemini avoidance test, San Diego Instruments, San Diego, CA). Training session was performed one day after drug treatment. Animals were placed in the safe compartment with a light off. Training started when a light was turned on. Animals received a single inescapable foot shock $(0.4 \mathrm{~mA}, 2 \mathrm{~s}$ duration) when they entered the dark compartment. The retention test session was carried out $1.5 \mathrm{~h}$ (short-term memory, acquisition), $24 \mathrm{~h}$ and $48 \mathrm{~h}$ (long-term memory, consolidation) and $168 \mathrm{~h}$ (long-term memory, extinction) after training and was procedurally identical to training, except that no footshock was delivered. The same rats were used in shortterm memory and long-term memory tests sessions. The latency to reenter the darkened shock compartment with all four paws was recorded as the measure of retention. The upper-bound of $600 \mathrm{~s}$ was set up for this measure.

\subsection{Immunohistochemistry for Fos Expression}

One hour after the last injection, all rats were placed under deep pentobarbital anesthesia (50 mg/kg, i.p.) and killed by intracardial perfusion with $4 \%$ paraformaldehyde in $0.1 \mathrm{M}$ phosphate buffer, $\mathrm{pH}$ 7.4. This experiment was performed separately from the passive avoidance test using different animals. Brains were removed, post-fixed overnight in the same fixative at $4^{\circ} \mathrm{C}$, and stored at $4^{\circ} \mathrm{C}$ in $20 \%$ sucrose. Serial coronal sections of the brains were cut (35 $\mu \mathrm{m}$ sections) on a Microslicer ${ }^{\circledR}$ (DTK-1000, Dosaka EM, Kyoto, Japan), and sections were stored at $4^{\circ} \mathrm{C}$ in $0.1 \mathrm{M}$ phosphate-buffered saline (PBS) containing $0.1 \%$ sodium azide. Fos expressions were determined using immunohistochemistry. Free-floating sections were washed three times for $5 \mathrm{~min}$ in $0.1 \mathrm{M} \mathrm{PBS}$ and then incubated for $10 \mathrm{~min}$ in $0.1 \mathrm{M}$ PBS containing $0.6 \%$ hydrogen peroxide to eliminate endogenous peroxidases. After washing three times for $5 \mathrm{~min}$ in $0.1 \mathrm{M} \mathrm{PBS}$, sections were then incubated for $1 \mathrm{~h}$ in $0.1 \mathrm{M}$ PBS containing $2 \%$ bovine serum albumin (BSA), 5\% normal goat serum, and $0.2 \%$ Triton X-100 for blocking. Sections were incubated at $4{ }^{\circ} \mathrm{C}$ for $72 \mathrm{~h}$ with the rabbit polyclonal antibody (Fos, 1:400, Calbiochem, Cambridge, MA). After washing six times for $5 \mathrm{~min}$ each in $0.1 \mathrm{M} \mathrm{PBS}$, sections were incubated for $2 \mathrm{~h}$ with the secondary antibody (biotinylated goat anti-rabbit IgG, Vector Laboratories, Burlingame, CA). Amplification was performed with an avidin-biotin complex (Vectastain Elite ABC kit; Vector Laboratories), and the resulting reaction was visualized with 3,3-diaminobenzidine tetrahydrochloride (DAB) (Vector Laboratories). Immunoreactivity was quantified by counting the number of Fos-positive nuclei within a $0.01 \mathrm{~mm}^{2}$ grid placed over each area at $\times 100$ magnification. Average counts from six sections per animals were used in the statistical analysis.

\subsection{Statistical Analysis}

For the repeated passive avoidance test, a two-way repeated-measures ANOVA was performed to assess the overall differences between variables (treatment $\times$ time). Subsequently, behavioral results between the two groups were analyzed by one-tailed Mann-Whitney test because the $600 \mathrm{~s}$ ceiling was set for test session latencies. Immunocytochemical results between the two groups were estimated by a two-tailed Student's t-test. The criterion of significance was $\mathrm{p}<0.05$.

\section{Results}

\subsection{Effects of Milnacipran on Passive Avoidance Task}

A two-way repeated-measures ANOVA on repeated passive avoidance task did not show behavioral difference between milnacipran-treated rats and saline-treated rats. In the subsequent one-tailed Mann-Whitney test, the milnacipran-treated rats showed a trend for amelioration in memory extinction (168 h later) (although not statistically significant), but not in the memory acquisition (1.5 $\mathrm{h}$ later) and consolidation ( $24 \mathrm{~h}$ and $48 \mathrm{~h}$ later), when compared to saline-treated controls (Figure 1).

\subsection{Effects of Milnacipran on the Number of Fos Counting in Various Regions of Brain}

Brain regions (prefrontal cortex, nucleus accumbens, stria-

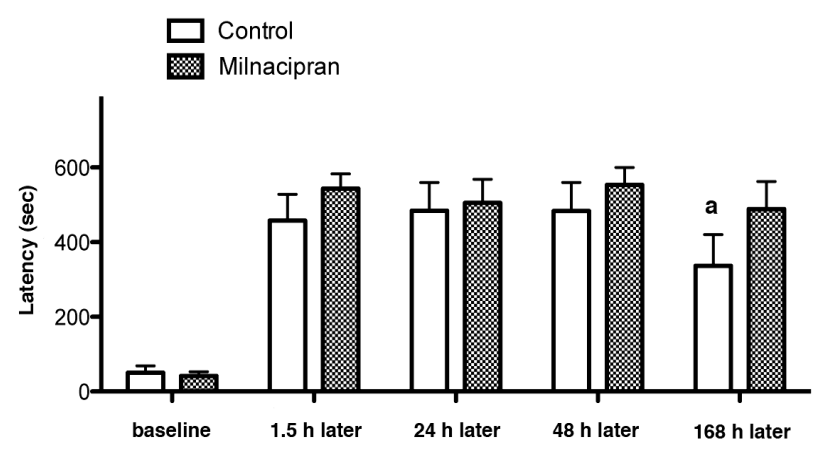

Figure 1. Effect of pre-training administration of milnacipran on short-term memory (1.5 $\mathrm{h}$ after training), long-term memory (24 and $48 \mathrm{~h}$ after training), and extinction (168 h after training) of inhibitory avoidance task. ${ }^{\mathrm{a}} \mathrm{A}$ trend for change without statistical significance ( $p=0.065$ by MannWhitney test). 
tum, septum, amygdala and hippocampus) examined in the current study were shown in Figure 2. Milnacipran had significant treatment effects at various regions (Figure 3). In the prefrontal cortex, we observed a significant decrease in the infralimbic cortex, but not in the prelimbic cortex. In the nucleus accumbens, a significant decrease was seen in the shell portion, but not in the core portion. In the septum, a significant increase was seen in the lateral portion, but not in the medial portion. In the striatum and amygdala, no change was seen. In the hippocampus, a significant decrease was seen in the CA1 region, but not in the dentate gyrus and $\mathrm{CA} 3$ region.

\section{Discussion}

In the present study, milnacipran did not affect memory acquisition and consolidation, but showed a trend for ameliorating memory extinction (although not statisticcally significant) in the passive avoidance test. It remains unknown whether this ability is related with antidepressant effects of milnacipran. However, depression produces deficits with memory [1]. The antidepressant effect might involve learning and memory because past aversive memory results in recurrent considering the past in depression. A recent study extrapolated that the effects of SSRIs are memory phase-dependent, being inhibitory during acquisition/consolidation and facilitatory during consolidation and retrieval [5].
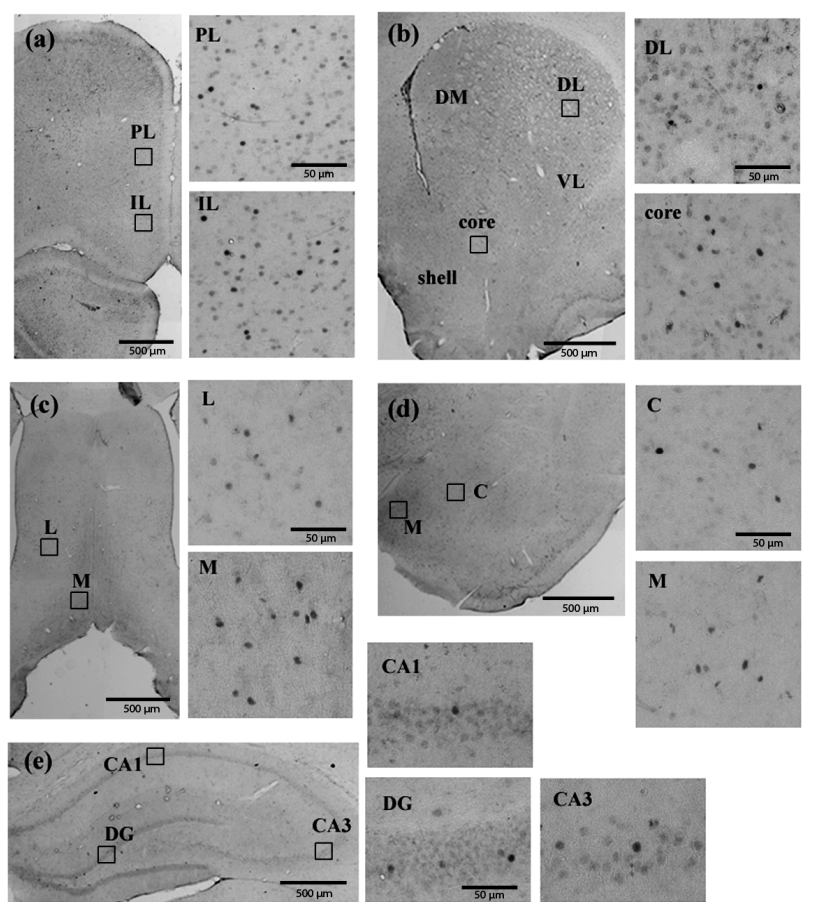

Figure 2. Fos immunoreactivity in the prefrontal cortex (a); Nucleus accumbens and striatum (b); Septum (c); Amygdala (d) and hippocampus (e). PL, prelimbic; IL, infralimbic; DM, dorsomedial; DL, dorsolateral; VL, ventrolateral; L, Lateral; M, medial; C, central; DG, dentate gyrus. (a)

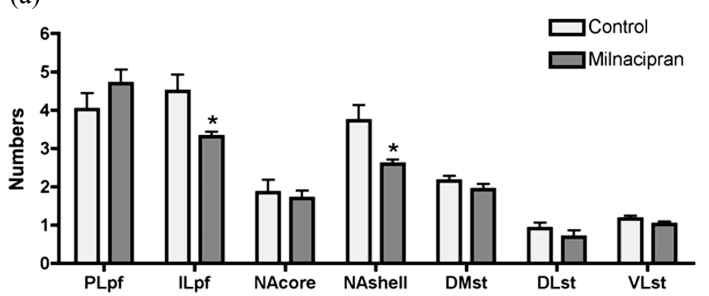

(b)

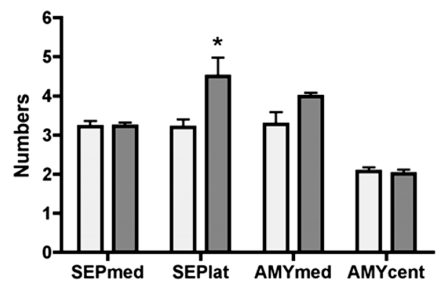

(c)

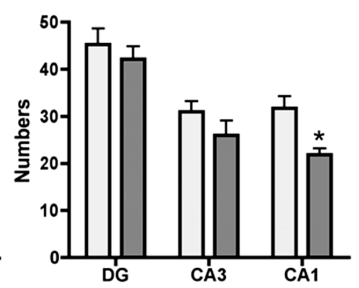

Figure 3. Distribution patterns of Fos-positive cells (mean number \pm S.E.M.) induced by treatments with milnacipran or saline. (a) Prefrontal cortex, nucleus accumbens, striatum; (b) Septum, amygdale; (c) Hippocampus. ${ }^{*}$ p $<0.05$ compared to respective control; $\mathrm{PL}$, prelimbic; IL, infralimbic; pf, prefrontal cortex; NA, nucleus accumbens; DM, dorsomedial; DL, dorsolateral; VL, ventrolateral; ST, striatum; SEP, septum; med, medial; lat, lateral; cent, central; AMY, amygdala; DG, dentate gyrus.

Extinction is supposed to be a result of the leaning of something new but not forgetting past because extinction involves the synthesis of new proteins in the hippocampus [11]. Antidepressant treatment alters plasticity-related protein in the hippocampus and medial prefrontal cortex $[12,13]$. In this context, the present result could be related with memory-related feature of antidepressant drug.

Previous studies demonstrated that acute administration of imipramine and citalopram, but not fluoxetine and desipramine, decreased Fos counts in the shell portion of nucleus accumbens [14,15], indicating the existence of drug's special features unrelated to selective serotonin reuptake inhibitor (SSRI) or SNRI. The anatomical information shows that the ventral shell portion receives innervations from the infralimbic region of medial prefrontal cortex and ventral hippocampus [16]. The nucleus accumbens seems to be relevant to depression and antidepressant action [17].

The infralimbic subregion of the medial prefrontal cortex plays a role in the extinction of fear memory since infralimbic stimulation reduced fear responses [18]. Chronic treatment with imipramine, desipramine and sertraline down-regulated stress-induced expression in c-Fos mRNA in the frontal cortex [19]. In the present study, repeated administration of milnacipran reduced Fos counts in the infralimbic region. The same treatment with milnacipran increased dopamine levels in the prefrontal cortex [8]. There may be some relationships between dopamine and 
extinction in the infralimbic region.

It is well documented that inescapable stress produces a change in synaptic plasticity in the hippocampal CA1 area [20]. Furthermore, milnacipran suppressed the longterm potentiation in the hippocampal CA1 field of anesthetized rats [21]. Anatomically, the hippocampal CA1 region gives rise to projections to the nucleus accumbens shell and infralimbic cortex [22], both of where Fos counts were decreased in the present study. It is conceivable that milnacipran exerts its actions in the nucleus accumbens shell and infralimbic cortex through attenuating neuronal activities in the CA1 region.

Lateral septum receives inputs from the hippocampus via the fimbria, and is thought to provide antidepressantslike effects [23]. A previous study showed that forced swim stress increased Fos counts in the lateral septum, but chronic administration of imipramine and fluoxetine did not block the alteration [24]. Exposure to a predator increased serotonergic neurotransmission in the septum as well as in the hippocampus and prefrontal cortex [25]. Therefore, the increases in Fos counts in the lateral septum by chronic milnacipran might response to compensate stress, although this is a speculation. It will be necessary to elucidate the role of septum in stress.

\section{Conclusion}

Milnacipran decreased the number of Fos-immunoreactive cells in the infralimbic prefrontal cortex, the nucleus accumbens shell and the hippocampal CA1 region, and increased Fos counts in the lateral septum. Behaviorally, milnacipran ameliorated (not statistically significant) memory extinction. The results could be new pharmacological profile of milnacipran.

\section{REFERENCES}

[1] T. Ellwart, M. Pinck and E. S. Becker, "Selective Memory and Memory Deficits in Depressed Inpatients," Depression and Anxiety, Vol. 17, No. 4, 2003, pp. 197-206.

[2] M. C. Arenas, C. Vinader-Caerols, S. Monleon, A. J. Martos, E. Everss, A. Ferrer-Ano and A. Parra, "Are the Effects of the Antidepressant Amitriptyline, Maprotiline, and Fluoxetine on Inhibitory Avoidance State-Dependent?" Bahavioral Brain Research, Vol. 166, No. 1, 2006, pp. 150-158. doi:10.1016/j.bbr.2005.07.020

[3] S. Monleon, A. Urquiza, M. C. Arenas, C. VinaderCaerols and A. Parra, "Chronic Administration of Fluoxetine Impairs Inhibitory Avoidance in Male but Not Female Mice," Behavioral Brain Research, Vol. 136, No. 2, 2002, pp. 483-488. doi:10.1016/S0166-4328(02)00194-8

[4] P. Pereira, J. Gianesini, C. da Silva Barbosa, G. F. Cassol, R. G. Von Borowski, V. F. S. Kahl, S. E. Cappelari and J. N. Picada, "Neurobehavioral and Genotoxic Parameters of Duloxetine in Mice Using the Inhibitory Avoidance Task and Comet Assay as Experimental Models," Phar- macological Research, Vol. 59, No. 1, 2009, pp. 57-61. doi:10.1016/j.phrs.2008.09.014

[5] S. Monleon, C. Vinader-Caerols, M. C. Arenas and A. Parra, "Antidepressant Drugs and Memory: Insights from Animal Studies," European Neuropsychopharmacology, Vol. 18, No. 4, 2008, pp. 235-248.

doi:10.1016/j.euroneuro.2007.07.001

[6] D. Mochizuki, R. Tsujita, S. Yamada, K. Kawasaki, Y. Otsuka, S. Hashimoto, T. Hattori, Y. Kitamura and N. Miki, "Neurochemical and Behavioural Characterization of Milnacipran, a Serotonin and Noradrenaline Reuptake Inhibitor in Rats," Psychopharmacology, Vol. 162, No. 3, 2002, pp. 323-332. doi:10.1007/s00213-002-1111-5

[7] Y. Kitaichi, T. Inoue, T. Izumi, S. Nakagawa, A. Kato and T. Koyama, "Subchronic Milnacipran Treatment Increases Basal Extracellular Noradrenaline Concentrations in the Medial Prefrontal Cortex of Rats," European Journal of Pharmacology, Vol. 520, No. 1, 2005, pp. 37-42. doi:10.1016/j.ejphar.2005.08.004

[8] K. Muneoka, Y. Shirayama, M. Takigawa and S. Shioda, "Brain Region-Specific Effects of Short-Term Treatment with Duloxetine, Venlafaxine, Milnacipran and Sertraline on Monoamine Metabolism in Rats," Neurochemical Research, Vol. 34, No. 3, 2009, pp. 542-555. doi:10.1007/s11064-008-9818-2

[9] O. Izquierdo and J. H. Medina, "Memory Formation: The Sequence of Biochemical Events in the Hippocampus and Its Connections to Activity in Other Brain Structure," Neurobiology of Learning and Memory, Vol. 68, No. 3, 1997, pp. 285-316. doi:10.1006/nlme.1997.3799

[10] J. P. Reneric and I. Lucki, "Antidepressant Behavioral Effects by Dual Inhibition of Monoamine Reuptake in the Rat Forced Swimming Test," Psychopharmacology, Vol. 136, No. 2, 1998, pp.190-197. doi: $10.1007 / \mathrm{s} 002130050555$

[11] M. R. M. Vianna, G. Szapiro, J. L. McGaugh, J. H. Medina and I. Izquierdo, "Retrieval of Memory for FearMotivated Training Initiates Extinction Requiring Protein Synthesis in the Rat Hippocampus," Proceeding of National Academy Science, Vol. 98, No. 21, 2001, pp. 12251 12252.

[12] M. Iwata, Y. Shirayama, H. Ishida and R. Kawahara, "Hippocampal Synapsin 1, Growth-Associated Protein-43, and Microtuble-Associated Protein-2 Immunoreactivity in Learned Helplessness Rats and Antidepressant-Treated rats," Neuroscience, Vol. 141, No. 3, 2006, pp. 1301-1313. doi:10.1016/j.neuroscience.2006.04.060

[13] M. Sairanen, O. F. O’Leary, J. E. Knuuttila and E. Castren, "Chronic Antidepressant Treatment Selectively Increases Expression of Plasticity-Related Proteins in the Hippocampus and Medial Prefrontal Cortex of the Rat," Neuroscience, Vol. 144, No. 1, 2007, pp. 368-374. doi:10.1016/j.neuroscience.2006.08.069

[14] C. H. Beck, "Acute Treatment with Antidepressant Drugs Selectively Increases the Expression of c-Fos in the Rat Brain," Journal of Psychiatry and Neuroscience, Vol. 20, No. 5, 1995, pp. 25-32.

[15] M. Morelli, A. Pinna, S. Ruii and M. Del Zompo, "Induction of Fos-Like Immunoreactivity in the Central Ex- 
tended Amygdala by Antidepressant Drugs," Synapse, Vol. 31, No. 1, 1999, pp. 1-4. doi:10.1002/(SICI)1098-2396(199901)31:1<1::AID-SYN $1>3.0 . \mathrm{CO} ; 2-\mathrm{S}$

[16] H. J. Groenewegen, H. W. Berendse, J. G. Wolters and A. H. Lohman, "The Anatomical Relationship of the Prefrontal Cortex with the Striatopallidal System, the Thalamus and the Amygdala: Evidence for a Parallel Organization," Progress Brain Research, Vol. 85, 1990, pp. 95116. doi:10.1016/S0079-6123(08)62677-1

[17] Y. Shirayama and S. Chaki, "Neurochemistry of the Nucleus Accumbens and Its Relevance to Depression and Antidepressant Action in Rodents," Current Neuropharmacology, Vol. 4, No. 4, 2006, pp. 277-291. doi: $10.2174 / 157015906778520773$

[18] M. R. Milad, I. Vidal-Gonzalez and G. J. Quirk, "Electrical Stimulation of Medical Prefrontal Cortex Reduces Conditioned Fear in a Temporally Specific Manner," Behavioral Neuroscience, Vol. 118, No. 2, 2004, pp. 389394. doi:10.1037/0735-7044.118.2.389

[19] S. Morinobu, H. Strausbaugh, R. Terwilliger and R. S. Duman, "Regulation of c-Fos and NGF1-A by Antidepressant Treatments," Synapse, Vol. 25, No. 4, 1997, pp. 313-320. doi:10.1002/(SICI)1098-2396(199704)25:4<313::AID-S $\underline{\mathrm{YN} 1>3.0 . \mathrm{CO} ; 2-\mathrm{D}}$

[20] T. J. Shors, T. B. Seib, S. Levine and R. F. Thompson, "Inescapable versus Escapable Shock Modulates LongTerm Potentiation in the Rat Hippocampus," Science, Vol.
244, No. 4901, 1989, pp. 224-226. doi:10.1126/science. 2704997

[21] K. Tachibana, M. Matsumoto, H. Togashi, T. Kojima, Y. Morimoto, O. Kemmotsu and M. Yoshioka, "Milnacipran, a Serotonin and Norepinephrine Reuptake Inhibitor, Suppresses Long-Term Potentiation in the Rat Hippocampal CA1 Field via 5-HT1A Receptors and Alpha 1-Adrenoceptors," Neuroscience Letter, Vol. 357, No. 2, 2004, pp. 91-94. doi:10.1016/i.neulet.2003.11.016

[22] I. Walaas and F. Fonnum, "Biochemical Evidence for Glutamate as a Transmitter in Hippocampal Efferents to the Basal Forebrain and Hypothalamus in the Rat Brain," Neuroscience, Vol. 5, 1980, pp. 1691-1698. doi:10.1016/0306-4522(80)90088-3

[23] T. P. Sheehan, R. A. Chambers and D. S. Russell, "Regulation of Affect by the Lateral Septum: Implications for Neuropsychiatry," Brain Research Review, Vol. 46, No. 1, 2004, pp. 71-117. doi:10.1016/j.brainresrev.2004.04.009

[24] G. E. Duncan, D. J. Knapp, K. B. Johanson and G. R. Breese, "Functional Classification of Antidepressants Based on Antagonism of Swim Stress-Induced Fos-Like Immunoreacitivity," Journal of Pharmacology and Experimental Therapeutica, Vol. 277, 1996, pp. 1076-1089.

[25] M. Beekman, C. Flachskamm and A. C. E. Linthorst, "Effects of Exposure to a Predator on Behaviour and Serotonergic Neurotransmission in Different Brain Regions of C57bl/6N Mice," European Journal of Neuroscience, Vol. 21, No. 10, 2005, pp. 2825-2836. doi:10.1111/j.1460-9568.2005.04107.x 